\title{
REVISITANDO UMA HISTÓRIA GUARDADA NO TEMPO: ESTUDO DO GÊNERO DISCURSIVO CARTA DE AMOR À LUZ DE TEORIAS BAKHTINIANAS
}

Luciane Watthier

\section{RESUMO}

Como parte de uma pesquisa de mestrado, esse trabalho pauta-se na compreensão de que os gêneros discursivos são modelos de enunciados relativamente estáveis produzidos por cada uma das esferas sociais visando a interação verbal. Sendo assim, o mesmo tem como objetivo realizar um estudo da linguagem dentro do gênero discursivo carta de amor. O propósito reside em compreender suas características definidoras, pautando-nos na ordem metodológica para estudos da língua sugerida por Bakhtin (2000, 2004), a qual contempla os três elementos composicionais dos gêneros discursivos, ou seja, conteúdo temático, construção composicional e estilo. Busca-se, portanto, nesses enunciados, além de traços estruturais, marcas reveladoras de história, cultura e identidade. Neste artigo, porém, nosso estudo está centrado, principalmente, no conteúdo temático e no estilo do gênero enfocado. Para isso, o corpus está constituído por uma carta de amor escrita por Neusa a seu então namorado, Armando, no ano de 1957. O referencial teórico é constituído, ainda, por Marcuschi (2003), Baltar (2004), Bazerman (2006), Basílio (1991), Dolz e Schneuwly, entre outros.

Palavras-chave: Gênero discursivo carta de amor; Conteúdo temático; Construção composicional; Estilo 


\title{
REVISITING A STORY STORED IN TIME: STUDY OF THE DISCURSIVE GENRE LOVE LETTER UNDER BAKHTINIAN THEORIES
}

\begin{abstract}
As part of a Masters research, this work is guided on the understanding that discursive genres are relatively stable models of statements produced by each of the social spheres looking for verbal interaction. Thus, it aims to conduct a study of language within the discursive genre love letter. The purpose is to understand its defining characteristics, guided by methodological studies of the language suggested by Bakhtin (2000, 2004), which includes three compositional elements of genres, which are thematic content, compositional construction and style. In these statements, therefore, we search, as well as, structural lines, marks of history, culture and identity. In this article, however, our study is focused primarily on the thematic content and style of the focused genre. For this, the body is made up of a love letter written by Neusa to her boyfriend at the time, Armando, in 1957. The theoretical reference is constituted also by Marcuschi (2003), Baltimore (2004), Bazerman (2006), Basil (1991), Schneuwly and Dolz, among others.
\end{abstract}

Keywords: Discursive genre love letter; thematic content; compositional construction; style

\section{Introdução}

A pesquisa aqui apresentada surgiu do interesse em analisarmos algumas cartas de amor recebidas por nosso falecido tio, Armando. Queríamos compreender o funcionamento concreto desses textos e, portanto, suas situações de produções. Já tínhamos conhecimento de alguns detalhes de sua vida pessoal e sabíamos, dessa forma, que entre seus 23 e 35 anos de idade, ele havia sido um homem "conquistador", gostando de ver as mulheres implorando seu amor quando, na realidade, não tinha o interesse em manter um relacionamento sério.

Com a leitura das cartas, observamos que tais atitudes eram corriqueiras na vida de Armando, pois entre os textos encontrados, estavam os de quatro mulheres apaixonadas. Notamos, ainda, que, além daquilo que nos havia sido contado, as cartas revelavam ainda mais detalhes, não só em relação à identidade de Armando, mas, também, destas remetentes 
apaixonadas: Gerda, Neusa, Eny e Auria, bem como a aspectos culturais da época e do local em que foram escritas.

Assim, textos pertencentes ao gênero discursivo carta de amor constituem-se como verdadeiros documentos por registrarem a cultura de uma época, bem como a identidade reveladora do estilo de cada locutor (remetente das cartas) e interlocutor (destinatário). A partir daí, esse estudo começou a ser encaminhado com o objetivo de refletirmos sobre a forma como isso acontecia e, também, sobre o porquê de a linguagem ser reveladora de tais características.

Partindo da abordagem metodológica para o estudo da língua proposta por Bakhtin/Volochinov (2004), a qual sugere o estudo de gêneros discursivos a partir de seu conteúdo temático, estrutura composicional e estilo, nosso trabalho tem como objetivo geral realizar um estudo da linguagem dentro do gênero discursivo carta de amor, destacando aspectos reveladores da cultura da época em que esses textos foram produzidos e, também, da identidade das pessoas envolvidas nessa situação enunciativa.

Para este estudo, porém, discorremos apenas sobre o estilo, devido ao pequeno espaço que é disponibilizado no gênero artigo científico. Nosso corpus é composto por uma carta de amor escrita por Neusa, no ano de 1957, a Armando, frisando que respeitamos a escrita original das cartas.

Ressaltamos a contribuição desse trabalho para a área acadêmica pelo fato de realizar a análise de uma carta, ou seja, de um texto pertencente a esse gênero textual considerando, ademais do material escrito, todo o seu contexto de produção, a saber: o antes (quem a produziu, quando, para quem, onde) e o depois (quem a recebeu, em qual contexto social, quando, etc.). Dessa forma, contribuímos, também, para o ensino da língua portuguesa, uma vez que analisar textos na perspectiva aqui enunciada permite uma compreensão completa de um gênero textual, desde seu conteúdo temático em sua estreita relação com o contexto de produção, passando pela sua estrutura composicional, até seu estilo.

\section{Algumas reflexões teóricas}

Neste estudo, nossa base teórica são leituras de/sobre o círculo de Bakhtin (2000, 2002, 2004). Tal filósofo, partindo de uma abordagem sócio-enunciativa, de acordo com a qual a linguagem e o pensamento são constitutivos do homem, demonstrou que seu objeto de estudo pertencia aos mecanismos de interação verbal. De acordo com suas compreensões, a 
necessidade de comunicação é o que justifica a existência da língua, ou seja, sem língua não há interação e, sem interação, não há nenhum tipo de relação social, pois “todas as esferas da atividade humana, por mais variadas que sejam, estão sempre relacionadas com a utilização da língua" (BAKHTIN, 2000, p. 279), permitindo aos homens dizer e agir sobre o mundo, constituindo-o e sendo constituídos por ele.

Consideramos, assim, a linguagem como uma atividade social, um conjunto de signos capaz de representar e constituir o real e, portanto, produto de uma necessidade histórica do homem, criado devido à necessidade de trocar experiências e de se organizar socialmente. E, falando em signo, Bakhtin/Volochinov compreende que a palavra, durante a interação verbal, ganha diferentes sentidos, conforme o contexto em que é utilizada, sendo isso o que a constitui em signo social e ideológico. Dessa forma, não se trata apenas da imagem (forma) que cada palavra evoca em nossa mente ao ser pronunciada, conforme compreensões não-sociológicas, pois a ideologia, acrescida aos signos por Bakhtin e seu Círculo, permite-os adquirir vida, transformando-se em um símbolo e, assim, representando posicionamentos sociais, ideológicos.

É o que Zandwais, autora estudiosa de concepções bakhtinianas, explica:

se a palavra se inscreve em um lugar heterogêneo é porque ela, sendo sustentada pela forma, mas, ao mesmo tempo, "adquirindo vida" como símbolo, constitui a materialidade e a essência do ideológico, por meio da maneira como ela trabalha e se desloca de modo incessante nas relações de interações do cotidiano da sociedade (ZANDWAIS, 2009, p. 106).

Em outras palavras, para Bakhtin e seu círculo, a concepção de signo ideológico vai além de uma imagem projetada. Ela é carregada de ideologias do mundo social, ou seja, está relacionada com a cultura e a identidade e, por isso, a linguagem dá pistas da situação social em que foi produzida, de seu contexto de produção.

Quando o Círculo de Bakhtin aborda a linguagem, o que ganha destaque é o diálogo, considerado um meio de discussão cultural. Sua ocorrência está ligada, de forma direta e inseparável aos enunciados, definidos por ele como unidades reais da comunicação verbal, um todo de sentido, responsáveis por sua materialização. Desse processo também faz parte a enunciação, a qual se constitui, para Bakhtin/Volochinov (2004), em uma réplica do diálogo social.

Nesse sentido, a interação, seja ela verbal ou não-verbal, "efetua-se por meio de enunciados (orais e escritos), concretos e únicos, que emanam dos integrantes duma ou doutra 
esfera da atividade humana" (BAKHTIN, 2000, p. 279). A interação verbal se dá, pois, por meio de enunciados existentes na sociedade, o que facilita esse processo, pois cada um destes modelos possui suas finalidades comunicativas próprias: é o que Bakhtin denomina como “tipos relativamente estáveis de enunciados” (BAKHTIN, 2002, p. 279). Ao utilizá-los, moldamos-lhes conforme nossas necessidades de interação e nosso ato comunicativo. Trata-se dos gêneros discursivos.

Portanto, os gêneros discursivos podem ser compreendidos como lugares onde o(s) enunciado(s) se $\operatorname{organiza}(m)$, ganha(m) forma, materializa(m)-se linguisticamente, representando, assim, o discurso da esfera social que o constitui.

Bakhtin $(2000,2004)$ considera que a interação verbal realiza-se não por meio de uma linguagem descontextualizada, mas por discursos, com todos os elementos linguísticos e não linguísticos (verbais e não-verbais), os quais organizam os gêneros que, materializados em textos (orais e escritos), estão presentes no nosso dia a dia. Justifica-se, então, o fato de tratar esses enunciados relativamente estáveis como gêneros do discurso s, associando a noção de gênero à de discurso.

Os gêneros discursivos são, portanto, modelos de enunciados em particular, os quais circulam socialmente, tornando possível a existência da linguagem falada e escrita, uma vez que não haveria como produzir um novo enunciado a cada momento, sem qualquer referência para isso. Nessa perspectiva, o enunciado, uma "unidade real da comunicação verbal" (BAKHTIN, 2000, p. 293), organiza-se de forma mais ou menos estável para constituir um repertório de gêneros que vai diferenciando-se e ampliando-se à medida que a própria esfera se desenvolve e fica mais complexa, já que as possibilidades de atividade humana, por meio do uso da língua, são inesgotáveis.

Para Perfeito e Ritter, esses modelos de enunciados foram e são formados com a finalidade de se evitar o caos comunicativo. Segundo as estudiosas, "no processo interativo, sócio-historicamente situado, a escolha dos recursos expressivos pelos sujeitos, na construção de um enunciado, se dá no rol de outros enunciados, determinados por suas esferas de comunicação" (PERFEITO; RITTER, 2009, p. 02). Trata-se do contexto de produção, definidor de cada uma de nossas formas de expressões, determinando, inclusive, o gênero discursivo capaz de organizá-las.

Daí a importância da interação verbal, que permeia todas as formas de agir, e dos gêneros discursivos, responsáveis pela organização dos enunciados por meio dos quais nos comunicamos. Ao afirmarmos isso, respaldamo-nos em Bakhtin, pois, para este autor, quando 
falamos "utilizamo-nos sempre dos gêneros do discurso, ou seja, todos os nossos enunciados dispõem de uma forma padrão e relativamente estável de estruturação de um todo" (BAKHTIN, 2000, p. 301), o que significa dizer que todas nossas ações sociais são moldadas por um gênero.

Assim, os usos da língua não se dão por orações isoladas, mas, sim, por meio de formações potenciais de gêneros que atuam no interior da linguagem, definindo seu caráter dialógico.

Nessa perspectiva de estudo, Lima-Lopes (1999) comenta que as regularidades organizacionais de um gênero seriam elementos responsáveis pelo seu reconhecimento. Segundo o autor, "cada gênero carrega formas lexicais e sintáticas próprias, ligadas aos conteúdos informativos de cada um deles. Além da escolha interpessoal, comum, existe uma escolha conteudística, particular” (LIMA-LOPES, 1999, p. 384). Tais formas são, portanto, relativamente estáveis.

Em outras palavras, não podemos ver os gêneros discursivos por meio de formas estáticas. Dependendo das intenções discursivas do usuário, de seu conhecimento de mundo e da necessidade de adaptá-los à situação comunicativa, acrescentam-se novas características ao(s) enunciado(s), sem desconsiderar aquelas já existentes na esfera discursiva que imprime marcas próprias no conteúdo temático, no estilo e na composição desse gênero. Toda ação de linguagem sempre será constituída por um processo de inserção individual no social.

Como exemplo, podemos citar a carta, um gênero discursivo muito complexo, uma vez que, para cada situação socioenunciativa que o envolve, novas características são apresentadas. Para citar alguns desses modelos, recorremos a uma pesquisa de Souto Maior (2001). Com base no domínio discursivo de cada um deles, a autora os agrupa em diferentes nomeações. Ela postula que a carta, "independente do meio por que é enviada (correio, fax ou e-mail), faz parte de uma 'constelação' que agrupa diversos textos ”' (SOUTO MAIOR, 2001, p. 11), motivo pelo qual esse modelo de enunciado pode ser considerado enquanto "um gênero com subgêneros” (SOUTO MAIOR, 2001, p. 11). Por isso, necessita ser categorizado para podermos compreendê-lo.

Ao referir-se aos subgêneros, Souto Maior (2001) refere-se às variadas fórmulas assumidas pelo gênero em questão. Assim, aquelas cujos domínios discursivos são comerciais são denominadas cartas de resposta e de comunicado; as de domínios instrucionais são cartas de programa, circulares, respostas e de apresentação; as jornalísticas são cartas do leitor, do editor, aos leitores, aberta, propaganda, boas vindas; as jurídicas são as cartas de intimação; 
publicitários são respostas, confirmações, agradecimento, pedido; religiosas são as cartas de convite ou de comunicado; e as de saúde são cartas de programa, de comunicado.

Dentro dessa variação de subgêneros, Barbosa (1979) acrescenta, às correspondências pessoais, as cartas familiares e de amor, sendo esta última categoria citada o modelo constituinte de nosso corpus de pesquisa, o qual será analisado a partir do percurso metodológico proposto por Bakhtin, ou seja, a partir dos três elementos que os constituem: conteúdo temático, estilo e construção composicional, conforme explicitado na próxima seção.

\section{Percurso metodológico de análise de gêneros discursivos}

Bakhtin/Volochinov (2004) deixa clara a necessidade de estudarmos a língua em seus contextos de uso. Para isso, ele propõe uma determinada ordem metodológica, a qual escolhemos como constituinte da base para o desenvolvimento desta pesquisa. Segundo o autor, qualquer estudo da linguagem deve orientar-se a partir da seguinte ordem metodológica:

1. As formas e os tipos de interação verbal em ligação com as condições concretas em que se realiza.

2. As formas das distintas enunciações, dos atos de fala isolados, em ligação estreita com a interação de que se constituem os elementos, isto é, as categorias dos atos de fala na vida e na criação ideológica, que se prestam a uma determinação pela interação verbal.

3. A partir daí, exame das formas da língua na sua interpretação linguística habitual. (BAKHTIN/VOLOCHINOV, 2004, p. 124).

Frisamos que, quando Bakhtin propõe esse método de pesquisa, ele não aborda, ainda, os gêneros discursivos, mas, sim, a teoria dos atos de fala, a qual pode ser relacionada, a partir da publicação de Estética da Criação Verbal (BAKHTIN, 2000), aos gêneros discursivos, englobando seus três elementos constituintes, ou seja, "conteúdo temático, estilo e construção composicional" (BAKHTIN, 2000, p. 279). Dessa forma, pode-se realizar um estudo completo das formas de enunciação. Tal relação pode ser justificada com a seguinte explanação de Bakhtin:

O enunciado reflete as condições específicas e as finalidades de cada uma dessas esferas, não só por seu conteúdo (temático) e por seu estilo verbal, ou seja, pela seleção operada nos recursos da língua - recursos lexicais, fraseológicos e gramaticais -, mas também, e, sobretudo, por sua construção composicional (BAKHTIN, 2000, p. 279). 
Sendo assim, pautamo-nos, durante as análises aqui realizadas, no método sociológico de Bakhtin/Volochinov (2004), porém, considerando a relação entre a teoria dos atos de fala e os gêneros discursivos, como enunciados relativamente estáveis que moldam a linguagem. Portanto, o olhar para as cartas de amor será voltado sob os três prismas, ou seja, primeiramente, ao conteúdo temático e sua estreita relação com o contexto de produção, depois, à construção composicional e, por fim, ao estilo.

Quando Bakhtin/Volochinov fala em conteúdo temático, está referindo-se ao elemento que "se apresenta como a expressão de uma situação histórica imediata concreta" (BAKHTIN/VOLOCHINOV, 2004, p. 128). Nessa perspectiva, o conteúdo temático é determinado como o assunto sobre o qual se fala, vinculado à situação comunicativa em que foi criado, revelado, então, pelas formas linguísticas e pelos elementos não verbais da situação. Em outras palavras: estudar o conteúdo temático de um gênero significa extrapolar o que está dito no texto, relacionando a análise com o mundo real, localizando-a na história e definindo-a a partir de características culturais de uma época. O tema, portanto, é carregado de ideologias.

Justifica-se, assim, a importância dada por Bakhtin e seu círculo ao contexto de produção de um gênero discursivo. As formas linguísticas de um enunciado permitem apenas a significação do que está dito. O contexto de produção, por outro lado, determina as condições reais de uma enunciação, permite a compreensão da situação social em que aquele enunciado foi produzido, determinando o objetivo e a atitude responsiva ativa do interlocutor. A partir do contexto de produção e, assim, do estudo do tema, temos, conforme Bakhtin/Volochinov (2004), a língua vinculada à vida.

O segundo elemento a ser analisado em um gênero discursivo é a estrutura composicional, abordando a construção de um texto, o que permite reconhecê-lo como pertencente a determinado gênero, devido ao "tipo relativamente estável de enunciado" (BAKHTIN, 2000, p. 279). Assim, cada gênero possui regularidades organizacionais responsáveis pelo seu reconhecimento. Nesse sentido, não podemos ver os gêneros discursivos por meio de formas estáticas, pois eles podem ser adaptados a cada situação comunicativa, visto que toda ação de linguagem sempre será constituída por um processo de inserção individual no social.

Seguindo a metodologia antes exposta, o terceiro e último ponto de análise de um gênero discursivo é o estilo. Para o autor, "o enunciado - oral e escrito, primário e secundário, 
em qualquer esfera de comunicação verbal - é individual, e por isso pode refletir a individualidade de quem fala (ou escreve)" (BAKHTIN, 2000, p. 283). Trata-se, portanto, de um elemento que reflete a individualidade, a identidade de seu autor, sua visão de mundo e, sendo assim, está ligado à cultura do local e da época em que foi produzido, ao conteúdo temático. Nessa perspectiva, a língua, a cultura e a identidade são indissociáveis entre si, na medida em que, seguindo as concepções bakhtinianas, a primeira, sendo social, histórica e dinâmica, representa e constitui a realidade.

Como forma de compreendermos o gênero discursivo cartas de amor, a análise a ser desenvolvida nesse estudo objetiva identificar essas representações de mundo reveladas na sua produção.

\section{Descrição e análise das cartas de amor}

Na perspectiva de transpor, para a prática, as reflexões teóricas realizadas nas seções anteriores, nosso estudo volta-se, agora, para a análise de uma carta de amor escrita no ano de 1957.

Adotando a ordem metodológica para estudos da língua proposta por Bakhtin/Volochinov e descrita neste texto, a presente seção foi subdividida em duas partes: na primeira, com base em entrevistas realizadas com a família de Armando, apresentamos o contexto de produção das cartas de Neusa, descrevendo o conturbado relacionamento entre o casal; na segunda, abordamos o estilo de Neusa.

\subsection{A carta de Neusa e sua situação de interação discursiva}

A carta a ser aqui analisada foi escrita por Neusa a Armando, na tentativa de manter um relacionamento com essa pessoa, sem saber que o mesmo nunca se transformaria em um casamento, como era almejado por ela. Assim, revela-se um grande amor, entretanto, nem sempre correspondido e sincero por parte do pretendente.

Apesar de termos várias cartas de amor escritas a Armando, escolhemos a de Neusa por ser ela reveladora de uma enorme mágoa pelas atitudes e pela rejeição de seu amado. Neusa é autora de três cartas a que tivemos acesso, as quais foram escritas entre os anos de 1955 e 1957. Para a descrição do contexto de produção faremos referências a todas elas, visto 
relatarem partes diferentes da história de amor do casal. Entretanto, a partir da próxima sessão, a análise estará restringida àquela escrita no dia 10 de março de 1957.

De acordo com depoimentos coletados com familiares de Armando, Neusa foi a segunda namorada de Armando. Antes dela, ele teria namorado Gerda, quem teria sido deixada para que ele pudesse ficar com Neusa. É o que as datas das cartas comprovam, pois as correspondências a que tivemos acesso foram trocadas com Gerda em 1953, e com Neusa a partir de 1955 (06 de setembro). E na primeira carta dessa pessoa, já percebemos desentendimentos entre os dois, sendo a mesma da seguinte forma iniciada: "Apesar de saber que tu não queres ler, uma carta escrita por mim mas hoje me vendo necessitada arrisquei-me, mas não precisa ter medo de lê-la, pois vai, porém, te aquilo que quero avizar-te." (Ct. escrita por Neusa em 06 de setembro de 1955).

Compreendendo que os dois, provavelmente, já estavam brigados, podemos supor que namoravam há algum tempo, o que comprovamos, inclusive, porque, segundo relatos de familiares, eles ficaram juntos durante cinco anos e, em 1958, Armando já namorava Eny. Ou seja, Armando e Neusa namoravam desde 1952, época em que Armando ainda estava com Gerda, pois, no dia 09 de novembro de 1956 Neusa envia um cartão a Armando, marcando o quarto aniversário de namoro do casal, iniciado, portanto, no dia 09 de novembro de 1952.

Ainda segundo informações da família, Armando e Neusa se conheceram na comunidade rural de Fundo Alegre. Neusa era brasileira, negra e, acreditamos, foi esse um dos motivos para que o romance tenha chegado ao fim, pois o pai de Armando não permitiu sua união com uma mulher "de cor".

Como já apontado, recuperamos três cartas escritas por Neusa a Armando, nas quais constam as seguintes datas: 06 de setembro de 1955, 21 de novembro de 1956 e 10 de março de 1957. A característica marcante das três é, em meio a pouquíssimas declarações de amor, a revelação do sofrimento de Neusa por ser desprezada ou estar brigada com Armando.

Em 1956, Neusa escreve a Armando poucas palavras e, mais uma vez, para contar suas mágoas em relação às atitudes dele frente à morte do pai dela. Sua reclamação é pelo fato de ele não ter respeitado tal acontecimento, não ter lhe dado forças para enfrentar o momento e, dois dias depois, já ter frequentado bailes: “[...] Deus chamou meu saudoso paizinho numa sexta-feira, quando foi domingo tu já foste num baile, e dali sempre; francamente só em pensar que meu querido pai era o braço forte de nosso namoro [...].” (Ct. escrita por Neusa em 21de novembro de 1956).

Neusa deixa claro que o namoro dos dois era permitido por sua família, pois seu pai 
os apoiava, mas, mesmo assim, Armando não respeitou sua morte e, muito menos, a relação que tinha com Neusa. As mágoas reveladas por meio da carta são devido ao fato de Armando não ter lhe ajudado a superar essa perda.

Essa forma de escrever distingue-se daquela empregada na última carta assinada por Neusa, quando ela tenta continuar um assunto iniciado pessoalmente:

[...] Estando eu triste sem o que fazer, apesar de há poucos instantes tu ter saído daqui, mais como o tempo foi curto, vou continuar os assuntos por meio deste papel. Pois bem foi tão curta tua visitinha que fiquei imaginando o viver; mas enfim consola-me, porque mais vale o pouco do que o nada [...] (Ct. escrita por Neusa em 10 de março de 1957).

Neusa fala a Armando sobre a alegria que sua visita lhe causa e, também, diz ter ficado muito magoada por essa ter sido muito curta. Isso mostra que, mesmo pouco, os dois se encontravam pessoalmente, entretanto, não tinham muita privacidade para certos assuntos, visto que ela parece ter preferido discutir sobre a relação entre os dois por meio das cartas, como pode ser observado no seguinte recorte:

[...] Meu bem! Nestes dias fiquei muito sentida, me contaram que tu cempre dançava varias pessas nos bailes com as Hichmann, para me fazer birra, ou seja, para ser o contra que eu te falava; e que cempre tu negavas a todo mundo nosso amor. [...] (Ct. escrita por Neusa em 10 de março de 1957).

Aqui, Neusa se refere ao fato de ele ter dito a outras pessoas que não queria nada com ela, não gostava dela. Toda a carta se volta a descrever sua dor e implorar algum sentimento de Armando. Ela afirma perceber, assim, que seu namorado tinha vergonha de acompanhá-la em público, negando seu amor. Por isso, acreditamos que o final desse relacionamento tenha ocorrido por Neusa ser uma mulher negra.

Conforme Semprini, ao trabalhar com a imigração nos Estados Unidos, fala do racismo "gota de sangue" (1999, p. 17), um processo de exclusão sofrido pelo indivíduo pelo fato de ser considerado negro quando era branco e tinha um bisavô negro, acreditamos que um tipo de racismo semelhante ocorreu no Brasil, afetando, também, o namoro entre Armando e Neusa. Devido ao fato de Neusa ser brasileira, de sobrenome Souza, e uma pessoa negra, inferimos que Armando, uma pessoa branca, descendente de alemães, tinha vergonha de estar com ela, ocultando-a em público.

Com esse sentimento de recusa, Neusa, então, descreve sua dor e faz uma reflexão sobre seu namoro com Armando e a forma com ele a tratava: 
Obrigado a meu amar, tu não és, mas a não me fazer sofrer tu és. Porque eu te considerando tanto e tu em público me ocultar, ou queres me fazer piraça, foi demais [...]. Faz um exame de conciencia, veja o que tu falaste desse modo ofensivo. (Ct. escrita por Neusa em 10 de março de 1957).

A seguir apresentamos a transcrição da carta escrita em 10 de março de 1957, conforme sua versão original. Nossa referência a ela é feita como Ct.1.

Armando!

“Benção dos Pampas. 10-3-57

Estando eu triste sem o que fazer, apesar de há poucos instantes tu ter saído daqui, mais como o tempo foi curto, vou continuar os assuntos por meio deste papel.

Pois bem foi tão curta tua visitinha que fiquei imaginando o viver; mas enfim consolame, porque mais vale o pouco do que o nada. $\mathrm{O}$ padrinho que ficou muito discontente tu não esperar para almoçar, porque como amanhã era teus anos ele mandou nós se aprontar para se caso tu viesse, nós te apresentar algo regular na mesa; e tu veio e não quis almoçar, ele me falou, eu fiquei muito sem jeito quando ele me falou. Meu bem! Nestes dias fiquei muito sentida, me contaram que tu cempre dançava varias pessas nos bailes com as Hichmann, para me fazer birra, ou seja, para ser o contra que eu te falava; e que sempre tu negavas a todo mundo nosso amor. Que tanta maldade te fiz eu para tu me fazer sofrer tanto? Que tu não queria ser acompanhado comigo ao publico, e que nosso amor era negado em publico, quando as gorias te falam tu dizes eu não tenho nada com ela, e não gosto dela.

Ai veio em minha memoria um baile que eu queria que tu fosse comigo na [incompreensível] quando João e dona Vina estavam aqui; e tu não quiz ir, e nos outros bailes dali uma semana foste, e não perde baile a parte nem uma. Quando me contaram esta, ai pensei á é verdade ele não quer me acompanhar no público, por isso ele não quis ir, esta sim

foi grande, eu não esperava de receber tal coisa de teu bondoso coração, sendo que eu te considero tanto aqui em casa, como em qualquer lugar, seja em vila, cidade, no meio dos meus parentes etc.

Obrigado a meu amar, tu não és, mas a não me fazer sofrer tu és. Porque eu te considerando tanto e tu em público me ocultar, ou queres me fazer piraça, foi demais. Não sei como é que eu sou tão apercegida dessa maneira. Francamente senti muito como essas; Olha meu coracãozinho fosse te fazer uma coisa dessa para ver se tu não se sentia; ainda mais se fosse duma pessoa que tu considerava o rei do amor e a baldade em?!... O que tu achas; Faz um exame de consciência, veja o que tu falaste desse modo ofensivo. Muitos e muito dias eu pegava na pena, e queria te escrever e não tinha força, meus olhos se enchiam de lágrimas e meu coração parece que se espedaçava de tanto sentimento, de ser tão pouco considerada."

"Contemplava a natureza e isto ainda me fazia sofrer mais ainda; me dava vontade de me sumir para bem longe num deserto para poder sofrer minha grande mágua no silêncio só em companhia dos pássaros da mata virgem.

Francamente não sei qual é o motivo do meu sofrimento; si sou merecedora, ou é porque não sou digna do teu amor; si é que tu não me acha digna para teu coração então me mande uma carta tua me mande exclarecer tudo bem direito, si não me amas; não me deixe sofrer tanto dessa maneira. Porque tu és a própria pessoa que eu tenho como testemunha, do tanto que eu te amo.

Porque ando tão solitária sem ter para quem me confessar minha grande magoa, e sem ter quem me console; tenho a te dizer quando tu juntou-me a teu peito por aquele afetuoso abraço, meu coração me perguntou a mim mesma está pessoa a quem tu tanto afeto transportou no momento sublime do abraço realmente te ama?... ou é como esses lambaceiros estão te enchendo sempre a cabeça... eu só respondi a 
mim mesmo eu de nada sei, só tenho a dizer que eu o amo como todo o meu ser, e me ser ainda é pequeno para abranjar todo o meu amor que eu possuo por ele. É triste a vida quando a gente não tem máxima certeza...

Armando quando tu estiveres no leito para dormir, recorda-te de mim e te imagina o meu sofrimento a minha agonia, não sei o que fazer, as vezes quero estar sorindo mas não posso; e ainda as vezes alguém começa a me chatiar mas te digo quase nem posso responder. Uma noite eu deitei e não pude dormir quando dei pela coisa pelas minhas faces se rolava ardentes lagrimas: Nestes dias tive ótima oportunidade para ir para o Entre-Ijuí, isto é no lugar onde mora o dr. Pereira, mas agradeci porque igual não tinha jeito para falar com as pessoas.

As vezes me esforço para rir para não dar demonstração da minha mágoa. Tu me achas mesquinha; mas de absoluto não sou, sou simplesmente uma grande sofredora: sem ter para quem me confessar: si me confesso a ti meu sofrimento me achas mesquinha, mas para quando não sou. É apenas o capricho do amor que fez de tudo um pouco. "Sou uma grande escrava do sofrimento". Hoje quando eu te vi, não posso explicar o meu contentamento a minha emoção, porque além de tudo fazia horas que eu não te vi; tudo isso ajudava na minha agonia. Peço-te uma grande favor que tu tire umas horinhas para me escrever sim?! Para poder melhorar um pouco a minha situação. Por meio desta, envio um forti daqueles de há poucos instantes à traz.

Adeus tua

Neusa M. de Souza”

\subsection{Dimensões valorativas e subjetivas de Neusa e Armando}

As reflexões sobre o contexto de produção da carta de amor de nosso corpus nos dá artifícios para a construção de um processo de identificação de Neusa e de Armando. Dessa forma, o estilo traduz-se na subjetividade do autor de um gênero discursivo, estando vinculado às identidades que lhe constituem, sua visão de mundo. Olhar para o estilo significa traçar contrapontos entre os valores sociais de uma comunidade e a forma como estes moldam o ser e o agir de seus indivíduos. Destacando Moita Lopes (2003), trata-se da visão de um indivíduo em relação ao mundo que o cerca, a si mesmo e, também, ao outro.

A partir da leitura da carta que compõe nosso corpus, concluímos que os grupos sociais daquela época eram mais retraídos, como forma de manter a honra da mulher. Não permitiam, portanto, que namorados tivessem muita privacidade. E, sendo a identidade formada por regras morais inculcadas do exterior, ou seja, da cultura, Neusa era uma pessoa pouco instruída, caseira e seus encontros com Armando eram bem reduzidos.

Segundo informações obtidas junto aos familiares de Armando, ela não dedicava muito tempo aos estudos e tinha como ocupação apenas os serviços domésticos, possuindo algumas dificuldades em trabalhar com a linguagem, as quais são demonstradas nos desvios gramaticais por ela apresentados. Entretanto, nada que afetasse a compreensão de suas cartas e as tornasse mais simples, pois sua linguagem é, também, reveladora de sentimentos verdadeiros, demonstrando todo seu amor. 
Apesar de ser a única herdeira de uma família, dona de muitas terras, era uma pessoa humilde, parecia não ter vergonha de declarar seu amor. Por outro lado, é impossível não perceber que Neusa era uma pessoa meiga, romântica e que, também, sofria muito por amor:

as vezes me esforço para rir para não dar demonstração da minha mágoa. Tu me achas mesquinha; mas de absoluto não sou, sou simplesmente uma grande sofredora: sem ter para quem me confessar: si me confesso a ti meu sofrimento me achas mesquinha, mas para quando não sou. É apenas o capricho do amor que fez de tudo um pouco. 'Sou uma grande escrava do sofrimento' [...] (Ct. 2).

A beleza dessa linguagem, tão reveladora, é o que nos faz sentir a tristeza dessas mulheres, tão apaixonadas, ao perceberem o desprezo da pessoa amada. Nesse sentido, Lopes (1986) destaca que a linguagem carrega valores culturais e identitários de cada falante, refletindo seu estilo, sua forma de ser e de agir, ou seja, transforma-se em um comportamento social, estando ligada à vida, à cultura e à história de um povo.

Só com base nessas leituras e na descrição do sofrimento dessa mulher, bem como do amor exagerado que ela nutria por seu amado, é possível apontar parte do estilo de Armando. Além de uma pessoa desprovida de maiores sentimentos (não se prendia a nenhuma mulher), parecia ser machista e controlador da situação. Esse aspecto identitário transparece na carta de Neusa:

[...] Obrigado a meu amar, tu não és, mas a não me fazer sofrer tu és. Porque eu te considerando tanto e tu em público me ocultar, ou queres me fazer piraça, foi demais. Não sei como é que eu sou tão apercegida dessa maneira. Francamente senti muito como essas; Olha meu coracãozinho fosse te fazer uma coisa dessa para ver se tu não se sentia [...] (Ct.1)

Armando parecia ter vergonha de expor suas relações sentimentais. Além de conquistador, iludia com cartinhas escritas, talvez, com menos frequência do que as recebia. Só o fato de mostrar-se um "homem difícil de ser conquistado", provocava a paixão em muitas mulheres. Percebemos, ainda, que era festeiro, pois mesmo namorando, não deixava de sair e ir a bailes, onde dançava com outras mulheres. Por tudo isso e pelo fato de trocar correspondências com Gerda e Neusa ao mesmo tempo, outro aspecto que define o estilo de Armando era ser infiel com suas namoradas.

Talvez fizesse isso pelo fato de ser uma pessoa segura, confiante em seus dotes físicos, revelados na elegância com que se vestia e na altivez de sua postura, achando que isso bastaria para torná-lo feliz. Chegamos, portanto, a duas conclusões a respeito do estilo de 
Armando: ele não queria manter um relacionamento sério ou, então não tinha a pretensão de um casamento, talvez por não acreditar nesse tipo de evento social.

Se é que um dia buscou a tão sonhada felicidade, ele o fez de forma errada, pois enquanto sabemos que Neusa está, hoje, casada, Armando já é falecido há treze anos, o que aconteceu depois de cair no vício da bebida e do cigarro e adquirir um câncer que lhe causou muita dor e sofrimento. Talvez ele tenha se arrependido de ter desprezado essa jovem amante, visto que as cartinhas, junto com algumas fotos, foram encontradas, após a sua morte, ainda muito bem conservadas, apesar de o tempo ter amarelado os papéis. Porém, provavelmente, muitos fatores o impediram de voltar atrás e ser, novamente, feliz.

\section{Considerações finais}

Ao iniciarmos esse trabalho, nosso objetivo era apresentar a análise de uma carta de amor a partir da ordem metodológica para estudos da língua proposta por Bakhtin/Volochinov (2004). Acreditamos ter conseguido abordar tais aspectos no material já citado e, ainda, que um trabalho de análise como esse poderia ser desenvolvido nas aulas de língua portuguesa. Isso propiciaria uma melhor compreensão da língua em seu funcionamento.

A análise da carta de amor de Neusa mostra que a linguagem é social, pois constitui a realidade, permitindo, por meio da análise realizada a compreensão do estilo das pessoas envolvidas nessa enunciação.

Nesse sentido, a linguagem deixa explícitas as peculiaridades próprias de um período da história, suas ideologias e sua cultura, bem como marcas de identidades. Quando temos mais de uma carta assinada pelo mesmo remetente, esses aspectos se revelam, cada vez mais, detalhados, podendo revelar, ainda, características da cultura e da identidade do destinatário das mesmas, pois foi dessa forma que conseguimos compreender um pouco mais da vida pessoal e do estilo de Armando.

Assim, quando Bakhtin propõe uma ordem metodológica de estudo da língua, contemplando o conteúdo temático, a construção composicional e o estilo, concordamos que seja esse o caminho de análise para a compreensão de um gênero discursivo. 


\section{Referências Bibliográficas}

BAKHTIN, Mikhail. Estética da Criação Verbal. [Trad. Maria E. Galvão e revisão por Marina Appenzeller]. 3. ed. São Paulo: Martins Fontes, 2000.

Marxismo e filosofia da linguagem: problemas fundamentais do método sociológico na ciência da linguagem. [Trad. Michel Lahud e Yara F. Vieira]. 11. ed. São Paulo: Hucitec, 2004.

BALTAR, Marcos. Competência discursiva e gêneros textuais: uma experiência com o jornal de sala de aula. Caxias do Sul: Educs, 2004.

BAZERMAN, Charles. "Atos de fala, gêneros textuais e sistemas de atividades: como os textos organizam atividades e pessoas" In: DIONÍSIO, Ângela Paiva; HOFFNAGEL, Judith Chambliss (org.). Gêneros textuais, tipificação e interação. Traduzido por Judith C. Hoffnagel. 2. ed. São Paulo: Cortez, 2006, p. 19 - 46.

DOLZ, J.; NOVERRAZ, M.; SCHNEUWLY, B. Gêneros orais e escritos na escola. [Tradução e organização de Roxane Rojo e Glaís Sales Cordeiro]. Campinas: Mercado de Letras, 2004.

LIMA-LOPES, Rodrigo Esteves de. "Cartas comerciais em língua inglesa: uma abordagem lexical”. Intercâmbio, vol.VIII, p.377-384. 1999.

LOPES, Edward. Fundamentos da Linguística Contemporânea. São Paulo: Cultrix, 1986.

MARCUSCHI, Luiz Antônio. "Gêneros textuais: definição e funcionalidade”. In: DIONÍSIO, Ângela Paiva; MACHADO, Anna Rachel; BEZERRA, Maria Auxiliadora (Orgs.). Gêneros textuais \& ensino. 2.ed. Rio de Janeiro: Lucerna, 2003, p. 19-36.

MOITA LOPES, Luiz Paulo da. 'Socioconstrucionismo: discurso e identidades sociais". In: Discursos de identidades: discurso como espaço de construção de gênero, sexualidade, raça, idade e profissão na escola e na família. Campinas: Mercado Letras, 2003, p. 13-38.

PERFEITO, Alba Maria; RITTER, Lílian Cristiana Buzato. "O editorial: uma proposta de análise linguística contextualizada". In: FERNANDES, Luiz Carlos (org). Interação: práticas de linguagem. Londrina: EDUEL, 2009, p. 153-173.

SOUTO MAIOR, Ana Christina. "O gênero carta - variedade, uso e estrutura". Ao Pé da Letra, p. 1-13, 2001. Disponível http://www.revistaaopedaletra.net/volumes/vol\%203.2/Ana_Christina_Souto_Maior-_genero_carta-variedade_uso_e_estrutura.pdf. 
ZANDWAIS, Ana. "Bakhtin/Volochinov: condições de produção de Marxismo e filosofia da linguagem”. In: BRAIT, Beth (org.). Bakhtin e o Círculo. São Paulo: Contexto, 2009. 